\title{
PROPUESTA DE INDICADORES AMBIENTALES PARA UN TURISMO SOSTENIBLE EN LA CIUDAD DE ZARAGOZA
}

\author{
S. Medrano Aranda \\ Graduada en Ciencias Ambientales \\ Escuela Politécnica Superior de Huesca (EPS-H). Universidad de Zaragoza \\ medranoaranda@gmail.com

\section{R. Lardiés-Bosque} \\ Departamento de Geografía y Ordenación del Territorio \\ C/ Pedro Cerbuna 12. 50009 Zaragoza. Universidad de Zaragoza \\ rlardies@unizar.es
}

\begin{abstract}
Resumen: Durante las dos últimas décadas, el rápido crecimiento del turismo y de las infraestructuras y servicios relacionados con esta actividad ha sido importante en el municipio de Zaragoza, por lo que es importante conjugar dicho crecimiento con criterios de sostenibilidad ambiental. Basado en el ámbito ambiental del concepto de desarrollo sostenible, en este artículo se propone un sistema de indicadores sobre turismo sostenible, con el fin de disponer de un instrumento de gestión que facilite la operacionalización del desarrollo sostenible de Zaragoza como destino turístico.
\end{abstract}

Palabras clave: indicadores, turismo sostenible, Zaragoza, propuesta, desarrollo sostenible.

\begin{abstract}
During the last two decades, the rapid increase of tourism activities, infrastructures and services associated with this activity, have been important in the city of Zaragoza; for this, it is essential to combine such growth with environmental sustainability criteria. Based on the environmental scope of the concept of sustainable development, a system of indicators for sustainable tourism is proposed in this paper, in order to provide a management tool to facilitate the operationalization of sustainable development in Zaragoza as a tourist destination.
\end{abstract}

Keywords: indicators, sustainable tourism, Zaragoza, proposal, sustainable development. 


\section{Introducción}

El turismo ha ido ganando importancia a lo largo de las ultimas dos décadas, hasta convertirse en una de las principales actividades económicas a nivel mundial. En particular, el auge del turismo urbano es una de las características de las sociedades actuales desarrolladas, lo cual ha permitido a las ciudades consolidarse como importantes destinos turísticos (De Esteban, 2008; OMT, 2013). Diversos factores han favorecido este proceso, entre los que destacan el desarrollo de estilos de vida ligados a la sociedad de ocio y la apuesta decidida de las ciudades por poner en valor una gran diversidad de recursos (centros comerciales, espectáculos musicales y deportivos, parques de ocio y experiencias ligadas al nuevo urbanismo, gastronomía y ocio nocturno). Tampoco hay que olvidar que la concentración de administraciones públicas y centros de decisión empresarial en entornos urbanos ha contribuido a la realización de negocios, congresos y ferias, atrayendo a un número cada vez mayor de visitantes y turistas (UrbanTur, 2013).

En paralelo al desarrollo del turismo, el debate sobre la sostenibilidad ha cobrado también un gran interés social, institucional y académico, sobre todo por la necesidad de definir herramientas con las que medir la evolución de los destinos turísticos en el proceso de transición que implica el desarrollo sostenible (Prados Pérez, 2002; Pulido y Sánchez, 2007; Vera Rebollo, 1992;). Nadie duda de los efectos positivos del turismo, pero debido a los efectos territoriales y al consumo de recursos que el desarrollo de estas actividades implica, actualmente preocupa especialmente su vinculación con el medio ambiente (García y De la Calle, 2012). También ha crecido la sensibilidad por los daños ambientales que esta actividad genera, dando lugar a un nuevo perfil de turista preocupado cada vez más por estas cuestiones (De Esteban, 2008). El desarrollo de un turismo sostenible implica el uso apropiado de los recursos naturales y culturales del destino en cuestión, la mejora la vida local y el crecimiento de los beneficios económicos que retroalimentan la economía local, incluido el turismo (Blancas et al., 2010). A los beneficios del desarrollo sostenible del turismo habría que añadir la consideración de este desarrollo sostenible como una estrategia necesaria para el equilibrio funcional de las ciudades (Troitiño, 1998).

El turismo se ha convertido en España en uno de los sectores de mayor peso en la economía del país, representando en 2012 el 10,9\% del Producto Interior Bruto (PIB) (INE, 2013). España es también el cuarto país del mundo con mayor número de turistas internacionales, y el primero de Europa y el segundo del mundo en cuanto a ingresos por turismo (OMT, 2013). Aunque las grandes cifras en el país se deben a la contribución de la modalidad de turismo de sol y playa, la riqueza monumental y los distintos eventos en diversas ciudades contribuyen al sostenimiento del sector (De Esteban, 2008; Troitiño, 2008).

Ciudades históricas como puedan ser Toledo, Segovia, Salamanca o Zaragoza, están cada vez más asociadas al turismo, por lo que es necesario reforzar la idea de sos- 
tenibilidad del turismo en ellas logrando crear un modelo turístico respetuoso con el patrimonio cultural y dando cabida a las nuevas demandas de accesibilidad y movilidad (Troitiño, 2000). Para poder realizar una gestión del flujo del turismo urbano es necesario definir capacidad de acogida o de carga de las ciudades y de los conjuntos monumentales, siendo éste un concepto clave para poder impulsar y lograr una estrategia de turismo sostenible en todas sus dimensiones (económica, social y medio ambiental) (García, 2000; PNUMA-OMT, 2006).

Teniendo en cuenta algunas variables y datos estadísticos del sector turístico, la ciudad de Zaragoza ha sido una de las que más ha crecido en el contexto nacional, y una en las que más se ha invertido en materia turística a lo largo de la última década, principalmente con motivo de la celebración de la Exposición Internacional de 2008 (Ruiz y De la Cal, 2008). Como ejemplo, Zaragoza ocupaba en 2010 el séptimo puesto entre las principales ciudades españolas en cuanto a número total de pernoctaciones, sólo por detrás de Madrid, Barcelona, Sevilla, Valencia, Granada y Santiago (INE, 2013). Según se reconoce en el Plan Estratégico Zaragoza Turismo 2011-2016 (Zaragoza Turismo, 2011), el crecimiento y la importancia de esta actividad refleja también el aumento del consumo de recursos como suelo, agua o energía, lo cual tiene implicaciones ambientales importantes, no siempre suficientemente conocidas, ni medidas, ni controladas de forma correcta. Por ello, y teniendo en cuenta la creciente importancia de Zaragoza como destino turístico, se puede afirmar que faltan instrumentos para poder mejorar la relación entre el turismo y el medio ambiente, por lo que en este trabajo, se destaca la posible implantación de un sistema de indicadores ambientales para hacer del turismo urbano una actividad más sostenible.

La propuesta del sistema de indicadores que aquí se realiza va precedida de la revisión de iniciativas emanadas de diferentes organismos internacionales y nacionales en relación a la sostenibilidad del turismo. La revisión también incluye el análisis de diversas experiencias en materia de sostenibilidad turística puestas en marcha en municipios y espacios urbanos en España, y de algunas medidas e instrumentos de gestión y planificación ambiental desarrollados a escala municipal. Finalmente, se prestará atención a las iniciativas llevadas a cabo para este fin en el municipio de Zaragoza.

En paralelo al análisis de experiencias previas, parece conveniente conocer algunas características de la evolución del sector, centradas en la oferta y la demanda en el municipio de estudio, ya que dicha evolución puede influir y condicionar el tipo y características de los indicadores. La propuesta que se realiza incluye cuarenta indicadores (cuantitativos y cualitativos) divididos en trece temáticas relacionadas con la sostenibilidad del turismo; cada indicador se ha recogido en una ficha cuyo diseño incluye la información básica y necesaria para su comprensión e implementación. 


\section{El turismo sostenible y el medio ambiente}

El sector turístico es particularmente sensible en sus relaciones con el medio ambiente, ya que por un lado consume recursos naturales y por el otro necesita un entorno natural atractivo para su desarrollo (Salinas y La O, 2006), aunque se desarrolle en espacios urbanos. Por esta razón, la protección del medio ambiente se ha convertido en necesidad desde finales de los años ochenta del siglo pasado, fundamentalmente a raíz del desarrollo del concepto desarrollo sostenible por parte de la Comisión Brundtland en 1987 (Lim y McAleer, 2005). Se trata de un concepto que hace alusión al desarrollo para satisfacer las necesidades del presente sin comprometer la capacidad de las generaciones futuras para atender sus propias necesidades (Villa, 2000). En consecuencia, el desarrollo turístico sostenible se ha definido como aquel que "atiende las necesidades de los turistas actuales y de las regiones receptoras, a la vez que protege y fomenta las oportunidades para el futuro" (OMT, 1978).

También a lo largo de las últimas décadas el turismo en espacios urbanos se ha demostrado una importante fuente de beneficios económicos, además de sociales y medioambientales, pero también de impactos negativos en el medio ambiente y en los distintos tipos de recursos existentes en los destinos (Ávila et al., 2002). Por esta razón, surge la necesidad de velar por la sostenibilidad de los espacios y destinos de turismo urbano, con el objetivo último de compatibilizar el desarrollo de esta actividad con el uso apropiado de los recursos naturales y culturales; esto implica, por un lado, asegurar la propia continuidad de la actividad turística (como generadora de ingresos), también la de los turistas, así como la mejora de la calidad de vida de la población local; por otro lado, el concepto implica velar por el entorno/destino, y en concreto por el estado actual y continuidad de los recursos, y por sus características esenciales tras su uso (Blancas et al., 2010).

Actualmente, se está de acuerdo en la necesidad de desarrollar el turismo con criterios de sostenibilidad, con la finalidad de implicar un cambio del paradigma en el aprovechamiento turístico de los recursos, compatibilizar el crecimiento con la eficacia en el uso de los recursos, garantizando una mejora en la calidad de vida de los residentes en los destinos y de los visitantes, a la vez que reconociendo que existen límites a la disponibilidad de recursos, por lo que deben tomarse medidas para reducir el consumo material que eleva los costes ambientales, culturales y sociales (Canizares Ruiz, 2013). Este cambio de paradigma, sin embargo, exige un equilibrio entre los objetivos a corto y a largo plazo, por lo que también implica implementar los procesos de toma de decisiones y las actuaciones relativas al uso de los recursos necesarias para alcanzar el escenario deseado (Pulido y Sánchez, 2007).

En consecuencia, el concepto de turismo sostenible se ha consolidado en la literatura académica y en las instituciones como pieza básica en el debate sobre la gestión de los recursos turísticos. Sin embargo, el corpus teórico y el pretendido desarrollo prác- 
tico del desarrollo sostenible de la actividad turística no se ha concretado en políticas eficaces capaces de garantizar que el aprovechamiento productivo del turismo sea compatible con la conservación del patrimonio natural y cultural del territorio en el que se desarrolla y con un modelo de gestión abierto y participativo (Pulido y Sánchez, 2007). Sobre esto, la OMT presento un informe en la Cumbre Mundial sobre Desarrollo Sostenible (Johanesburgo, 2002), en la que se destacó, por un lado, que la necesidad de aplicar en el turismo una planificación sistemática se ha convertido en un enfoque ampliamente aceptado, y que las políticas y estrategias de turismo recomendadas por las organizaciones internacionales incorporan la cuestión medioambiental y la sostenibilidad social y económica; sin embargo,, la aplicación efectiva de esos principios por gobiernos centrales, regionales y locales, y por los empresarios turísticos, ha sido lenta y parcial (Yunis, 2003). Esa falta de aplicación, seguramente responderá a los problemas existentes para medir la sostenibilidad.

\subsection{La medición de la sostenibilidad del turismo}

Medir y cuantificar la sostenibilidad no es una tarea sencilla, por varias razones (Pulido y Sánchez; 2007). Primero, porque el concepto de sostenibilidad, además de ser relativamente reciente, no deja de ser bastante abstracto, relativo, a la vez que latente, por lo que no es directamente observable, lo que obliga a ser cuantificado mediante indicadores indirectos que se relacionan, en mayor o menor medida, con la sostenibilidad. Segundo, porque la sostenibilidad tiene un carácter multivariante, puesto que son varios los aspectos con los que guarda relación, ya que la naturaleza social, económica, medioambiental e institucional a las que hace referencia justifican ese carácter. En tercer lugar, la medida de la sostenibilidad es relativa, en el sentido de que, dependiendo de la unidad de análisis que se tome como referencia, las unidades analizadas pueden ser más o menos sostenibles. Finalmente, está el problema de que su cuantificación, casi siempre, viene dada en diversas unidades de medida; esto ocurre, sobre todo, con los indicadores medioambientales, que suelen expresarse en unidades de medida de lo más variado (emisiones de $\mathrm{CO}_{2}$, tratamiento de residuos, producción de energías renovables), lo cual dificulta la valoración cuantitativa y la medición de la sostenibilidad.

\subsection{Los indicadores como herramienta para la sostenibilidad del turismo}

Una de las líneas desarrolladas sobre la sostenibilidad ha sido la identificación y medición de los impactos que genera la actividad turística sobre distintos tipos de destinos y recursos turísticos, en torno al desarrollo de "indicadores de presión turística" y de "capacidad de carga turística" (García, 2000; García y de la Calle, 2012). De hecho, el concepto de capacidad de carga ha sido uno de los instrumentos más utilizados para dar respuesta a los problemas de la afluencia masiva de visitantes en espacios recrea- 
tivos y para racionalizar el uso abusivo y el deterioro de los recursos que sustentan el desarrollo del turismo (García et al., 2011). Si bien los estudios de capacidad de carga turística tienen ya una larga trayectoria académica, los trabajos sobre la aplicación del concepto a espacios turísticos urbanos y monumentales son pocos todavía; en concreto, y sobre la capacidad turística en ciudades históricas y conjuntos monumentales en España, destacan los de Troitino et al. (1999) y García Hernández (2003), de gran contenido metodológico y aplicado.

Además, una de las herramientas más extendidas para el logro de la sostenibilidad medioambiental en los destinos turísticos ha sido los sistemas de indicadores (Castro, 2002). Desde principios de los años 90 del siglo XX en que comenzaron a discutirse propuestas de indicadores, diversos autores e instituciones han abordado cuestiones relacionadas con el concepto, las posibles definiciones, o sus funciones (OCDE, 1997; OMT, 1995; Sancho y García, 2006).

La creación de indicadores implica una construcción cientifico-tecnica, amparada en una valoración social previa, que otorga a determinados parámetros valores de representación sobre procesos relacionados con el desarrollo sostenible o, desde el punto de vista ambiental, con la presión sobre el medio, las condiciones ambientales objetivas y las políticas de respuesta (Ivars, 2001). Por lo tanto, los indicadores permiten comprender la situación actual, definir el estado ideal, y pronosticar si, con las actuaciones ejecutadas, se esta más o menos cerca de dicho estado, así como prevenir, anticipar y solucionar problemas (Bermejo y Nebreda, 1998). Básicamente, se trata de una forma simple de reducir y presentar información diversa, ya que con su uso se reduce el número de parámetros y medidas que normalmente serían requeridos para dar una presentación exacta de una situación (OCDE, 2003). En definitiva, se utilizan para determinar si en una zona determinada se está cumpliendo con los objetivos del desarrollo sostenible, medido en todas o en alguna de sus dimensiones (económica, ambiental, social e institucional) (Gutierrez-Fernandez et al., 2012).

Las tres funciones básicas de los indicadores son simplificar, cuantificar y comunicar (OCDE, 1997), por lo que permiten una lectura breve, comprensible y científicamente válida del fenómeno de estudio (OMT, citado por Castro, 2002). Según el mismo autor (Castro, 2002), las utilidades que se obtienen de los indicadores son:

- Modelización de los elementos del sistema: el análisis de los elementos que componen un sistema se realiza mediante un sistema de indicadores. Dicho sistema va a permitir relacionar los elementos y analizar así la evolución de las variables.

- Simulación: a partir del modelo descrito anteriormente se realiza un análisis de las variaciones que se producen alterando sólo algunos componentes y manteniendo el resto intactos, utilizando para dicho análisis los indicadores. 
Seguimiento y control de objetivos: establecidos unos objetivos, los indicadores van a permitir conocer el grado de consecución de éstos. A su vez, permiten conocer las causas que llevan a la situación del grado de consecución del objetivo.

Predicción: se puede prever un futuro tendencial al trabajar con indicadores, considerando la variación de las variables en el tiempo y cómo éstas afectan al sistema de indicadores.

Previamente a explicar la propuesta de sistema de indicadores ambientales sobre turismo, a continuación se hace una revisión de los propuestos por diferentes organismos o autores, incluidos los del entorno académico.

\subsection{Experiencias internacionales y nacionales sobre la aplicación de indicadores de turismo sostenible}

En este apartado se lleva a cabo la revisión de iniciativas relacionadas con la aplicación de sistemas de indicadores de turismo a distintas escalas territoriales. Esta revisión se realiza para conocer el desarrollo y aplicación de los instrumentos de sostenibilidad del turismo en el ámbito local, además de las temáticas y el tipo de indicadores existentes. También la propuesta se debe ajustar lo máximo a los indicadores puestos en marcha hasta el momento, considerando la información disponible sobre el sector turístico, además de tener que ser asumible técnica y económicamente.

La revisión se centra en indicadores simples, y excluye los indicadores sintéticos para el desarrollo sostenible, cuyo desarrollo es aún muy reciente, por lo que las aportaciones teóricas son todavía muy escasas (Pulido y Sánchez, 2007). No obstante, entre los sintéticos son referente el Monitor de Competitividad Turistica del WTTC, la aportacion al World Economic Forum (WEF) de los grupos de trabajo de las Universidades de Yale y de Columbia, que han disenado el Environmental Sustainability Index (ESI) y, para el caso de Espana, el trabajo realizado por un equipo de investigadores de la Universidad de A Coruna con el diseno de un Indice Sintetico de Desarrollo Sostenible (Synthetic Index of Sustainable Development, o SISD), que han aplicado al análisis del desarrollo sostenible de las Comunidades Autonomas con buen resultado (Pulido y Sánchez, 2007). Como se puede apreciar, son aportaciones para medir la sostenbilidad, pero no desde el ámbito del turismo.

A lo largo de las últimas décadas, y desde diversos organismos, instituciones y mundo académico, se han realizado distintas propuestas de indicadores para medir cuestiones relacionadas con aspectos ambientales, la oferta y la demanda del sector turístico, o de competitividad de los destinos (Rivas y Magadán, 2007).

Gutierez-Fernandez et al. (2012) hacen una valiosa recopilación de distintos tipos de indicadores de sostenibilidad para áreas naturales, incuyendo las temáticas ambiental 
y la del turismo (no siempre solapadas). En dicha revisión se recogen los indicadores más importantes existentes sobre sostenibilidad, algunos de los cuales se relacionan con el turismo; se trata de los 134 propuestos por UN-CSD (United Nations-Commission Sustainable Development) en 1996, y de los 57 posteriores en 2003; la OCDE también propuso 53 en 2003, y los 63 del Ministerio de Medio Ambiente de España en 2000. Además, la OMT creó otros 58 indicadores en 2004 sobre turismo (OMT, 2005).

Sin embargo, el desarrollo y seguimiento de las Agendas 21, al igual que de los Planes de Excelencia Turística y otros posteriores impulsados en diferentes destinos turisticos en el contexto de la política turística española (Beas Secall, 2012) han concentrado buena parte de los esfuerzos para la creación de indicadores de sostenibilidad turística (Ávila et al., 2002; Ayuntamiento de Zaragoza, 2012; Gomila, 2000). Se trata de planes (ambientales o sectoriales, sobre turismo) que han permitido avanzar en la implementacion de indicadores de sostenibilidad turistica, y que se han basado, fundamentalmente, en metodologias propuestas por organismos internacionales como la ONU, la IUCN y la OCDE. También habría que añadir las síntesis realizadas por la CEPAL sobre las iniciativas más relevantes en países de América Latina y el Caribe, aunque son parciales y escasos los instrumentos de medición del turismo (Quiroga Martínez, 2007).

A partir de las propuestas de los organismos anteriores, y sobre todo desde el año 2000, se ha entrado en una nueva etapa en la cual se han desarrollado estudios de planificación del turismo a escala local, considerando las condiciones específicas de cada territorio y sus caracteristicas economicas y sociales (Jimenez e Hirabayashi, 2003; Pardellas y Pandín, 2004). De esta última etapa destacan los sistemas de indicadores creados a escala regional, como los aplicables a zonas litorales cubanas (Salinas y La O, 2006) o a distintas zonas turísticas de Andalucía (Blancas et al., 2010; Pérez et al., 2009). De los trabajos realizados a esta estaca local también destacan indicadores creados para zonas con modalidades de turismo concretas, como el sistema propuesto por Gutierez-Fernandez et al. (2012) para áreas naturales con uso turístico, validado mediante consulta a terceros.

Según Gutierez-Fernandez et al. (2012), la mayor parte de los sistemas de indicadores de sostenibilidad en turismo incluyen indicadores ambientales (fisico-naturales), y en menor medida sobre temáticas de las otras dimensiones (económica, social e institucional). Además, y según estos autores, sólo algunos sistemas miden el desarrollo sostenible de acuerdo con lo propuesto por la Comision de Desarrollo Sostenible de las Naciones Unidas, destacando en materia de turismo las de la OMT (2005) y Choi y Sirakaya (2005).

No obstante, lo habitual es que las propuestas incluyan indicadores relacionados con diversas temáticas y no sólo centradas en lo exclusivamente ambiental; es el caso de la propuesta de la Unión Mundial para la Naturaleza (IUCN), que incorpora un método de evaluación de la sostenibilidad en el que se da igualdad de trato a personas y ecosistemas, por cuanto considera indicadores en dos grandes vertientes: veinte de carácter 
ecológico y otros veinte de carácter humano (IUCN, 2001). Otras propuestas como la desarrollada por Salinas y La O (2006) para zonas turísticas litorales de Cuba también utiliza indicadores en distintos ámbitos como el entorno geoecológico, la infraestructura turística, el cliente externo y el entorno socioeconómico. De igual modo, los indicadores propuestos Choi y Sirakaya (2005) se centran en aspectos ambientales relacionados con el turismo y miden la congestión de carreteras, las basura/polución (aire, agua, etc.), o la disponibilidad, tamano y condición del bosque urbano; sin embargo, su propuesta también abarca temáticas como la económica, con indicadores para comparar los salarios en turismo frente a los salarios de otros sectores, o de contabilidad ambiental, o para analizar el ciclo de vida, o sobre aspectos de salud para medir la conciencia publica hacia el valor del turismo.

También es reconocido el esfuerzo que han realizado los estados del Caribe para tratar de medir el grado de sostenibilidad de sus destinos turísticos, sobre cuya metodología usada por la Asociación de Estados del Caribe y la aplicada actualmente por la SECTUR (Secretaria de Turismo de México), con respaldo de la OMT en México, dan cuenta Ibanez y Angeles (2012). En febrero de 2004 se presento el primer Manual sobre los Indicadores de Sustentabilidad, que tras ser sometido a consideración por parte de la OMT, fue aprobado en 2006; esta metodología incluía cuatro tipos de indicadores (economico, social, cultural y ambiental), que combinados sumaban, en conjunto, catorce:

1) Seguridad,

2) Identidad y cultura,

3) Prostitución Infantil,

4) Empleo Turístico,

5) Calidad de los cuerpos de agua (marino y terrestre),

6) Calidad del agua para consumo humano,

7) Índice de consumo energético,

8) Índice de consumo de agua,

9) Uso y manejo ambiental,

10) Gestión ambiental,

11) Eficiencia del sistema de manejo de desechos sólidos,

12)- Eficiencia del sistema de manejo de desechos líquidos,

13)- Satisfacción del turista, y

14)- Índice de consumo de productos nacionales y locales.

Otras aportaciones son específicas para medir la competitividad del sector turístico mediante indicadores, aunque a escala nacional. Por ejemplo, el World Travel and Tourism Council (WTTC), en colaboración con el Instituto Christel DeHaan Travel Research (TTRI) 
de la Universidad de Nottingham, han desarrollado el "Monitor de Competitividad (CM)" para turismo con la finalidad de elaborar indicadores de referencia entre países (Gooroochurn y Sugiyarto, 2005). En concreto, el modelo de Ritchie y Crouch (2003) se considera el más importante para el análisis de la competitividad del turismo. Y también relacionado con la medición de la competitividad, otros autores han abordado conceptualmente la competitividad de los destinos turísticos desde la óptica de la relación existente con la gestión medioambiental y/o sostenible del turismo (Mazaro y Varzin, 2008); en concreto, estos autores han presentado un modelo denominado CompEtenible Model, que pretende ayudar a conocer y evaluar la implantación de acciones competitivas por parte de los destinos turísticos, en consonancia con un desarrollo sostenible.

En cuanto a experiencias de sostenibilidad del turismo en España, y antes de analizar las relacionadas con indicadores, se puede citar que diversos gobiernos han puesto en marcha iniciativas para la mejora ambiental del turismo, bien a través de organizaciones o proyectos impulsados desde Ministerios. Destacan algunas experiencias como la del Ministerio de Agricultura (con el Banco Público de Indicadores Ambientales), el de Medio Ambiente (Fundación CONAMA), por no citar las del desaparecido Observatorio de la Sostenibilidad en España (OSE), que fue una referencia importante en esta materia hasta 2013. También otros organismos como el Instituto de Turismo de España (TURESPAÑA) y algunas experiencias desarrolladas a nivel regional, han contribuido a impulsar la sostenibilidad económica, social y medio ambiental de los destinos turísticos y del sector en general (Ivars, 2001).

Siguiendo con las iniciativas en España, pero ya centradas en el desarrollo y aplicación de indicadores de turismo sostenible en municipios españoles, destacan las propuestas de la Federación Española de Municipios y Provincias (FEMP); en concreto, destaca la aplicación de la Agenda 21 Local, sobre todo en municipios capital de provincia y que cuentan con importante oferta cultural y monumental, principalmente en ciudades históricas (Troitiño, 2008; Troitiño et al., 2008). Entre 1994 y hasta 2008, numerosos municipios en España desarrollaron Agendas 21, siendo destacables las de Barcelona y la de Calvià (Estrategia Calvià + 10), puesta en marcha esta última desde 1994 e importante por su carácter pionero y por los notables beneficios ambientales que el desarrollo de este instrumento ha tenido en el municipio (Gomila, 2000). Además, conviene destacar a escala municipal diversos ejemplos de puesta en marcha de Observatorios de Turismo municipales, en los que se ha generalizado la aplicación de indicadores.

En Espala, y en materia de indicadores de sostenibilidad, los principales avances se han producido en el ámbito de la definición de los de tipo ambiental (Ministerio de Medio Ambiente, 2003), es decir, aquellos que facilitan la evaluación de la incidencia del turismo en el medio ambiente, mientras que la incorporación de las demás dimensiones del turismo sostenible (sociocultural, económica e institucional) se ha planteado, en la mayoría de los casos, a través de una adaptación de los modelos utilizados para la definición de indicadores ambientales. 
Sobre los distintos sistemas de indicadores, un problema es que no existe una lista de los universales y unánimemente aceptados, sino que muchos suelen estar fuertemente vinculados a los procesos de los que forman parte, por lo que las aportaciones realizadas hasta ahora sólo admiten una comparación muy parcial -variable a variable, o indicador a indicador-, ya que no establecen una forma homogénea, sintética y global para llevarla a cabo entre los distintos territorios o economías (González et al., 2004; Pulido y Sánchez, 2007). Con tal problema, y fruto de la revisión del conjunto de experiencias sobre sistemas de indicadores ambientales relacionados con el turismo, para este trabajo se ha recogido un total de 187 indicadores diferentes, a partir de los cuales se realizará la propuesta.

Otro aspecto importante a tener en cuenta para esta propuesta es conocer las características del turismo en Zaragoza, sobre todo lo relacionado con la oferta y demanda de turística (número y evolución de turistas, tipología, distribución temporal a lo largo del año, alojamientos y duración de la estancia, modo de transporte utilizado para realizar el viaje a la ciudad, etc.), ya que la situación y evolución de estos aspectos condicionará el tipo y características de los indicadores a utilizar. Por ejemplo, conocer la variación y el estado de la demanda turística influirá en el consumo de recursos, y en consecuencia, en incluir unos u otros indicadores para medir unas u otras variables. Por lo tanto, a continuación se analiza la evolución de la oferta y demanda de la actividad turística en el municipio de Zaragoza, para dar paso posteriormente al análisis de la utilización de estos instrumentos (indicadores) en el municipio.

\section{El desarrollo del turismo en el municipio de Zaragoza}

\subsection{El sector turístico de Zaragoza y su evolución: la oferta y la demanda}

La experiencia turística dependerá, entre otras cosas, de las necesidades que pueda satisfacer a quienes visiten la ciudad, y en ello tiene gran importancia la calidad de la oferta de equipamientos y recursos turísticos que ofrece el destino. La ciudad de Zaragoza presenta una gran oferta de estos recursos y equipamientos, lo que hace que la ciudad sea un destino atractivo para los turistas (Callizo y Lacosta, 2006).

Según opiniones de algunos responsables del Patronato de Turismo de Zaragoza y de la Oficina de Turismo de la Diputación General de Aragón, el rico patrimonio histórico y cultural de la ciudad se ha consolidado como el principal reclamo turístico, el cual sustenta la modalidad de turismo urbano y cultural como una modalidad turística en auge. En esta línea, los turistas atraídos por el patrimonio y la cultura de Zaragoza representan el 69\% de las visitas, seguido por la atracción del ocio y fiestas (Fiestas del Pilar y Ruta Cofrade en Semana Santa) (17\%) (Zaragoza Turismo, 2012). Además, el turismo de negocios, ferias y congresos destaca como el segundo tipo de motivaciones a la hora de visitar la ciudad (2\% de las visitas) (Zaragoza Turismo, 2012). 
El número de turistas que visitan Zaragoza ha aumentado, sobre todo a partir del 'pico' de 2008 con la celebración de la Exposición Internacional, que fue el gran evento que no sólo dotó a la ciudad de nuevos servicios e infraestructuras, sino que la dio a conocer internacionalmente (Zaragoza Turismo, 2013a). Se puede afirmar que la realización de la EXPO 2008 ha sido la 'excusa' y el arranque de la modernización que ha vivido la ciudad en los últimos años, habiéndose concebido este gran evento dentro de la estrategia de desarrollo para Zaragoza y su entorno (Pueyo, 2007); de esta forma, la EXPO 2008 fue el comienzo de una gran operación de renovación urbanística, de la mejora de la movilidad urbana en la zona metropolitana, y de la cruzada por el ahorro del agua y por el interés por convertir a Zaragoza en el paradigma de ciudad sostenible (Alonso y Belllet, 2009).

Actualmente, la ciudad cuenta con una gran oferta de zonas y grandes centros comerciales que atraen a visitantes y turistas a realizar compras, lo cual genera el 1\% de las visitas a la ciudad por interés de compras (Zaragoza Turismo, 2013a). También la gastronomía aragonesa es un atractivo, con los 712 establecimientos (entre bares y restaurantes) con los que contaba el municipio en 2013 (Zaragoza Turismo, 2013b).

Por último, la calidad ambiental ha sido el objetivo y el motor de las transformaciones asociadas a la EXPO 2008 (Pellicer, 2008), por lo que otro de los efectos de este evento ha sido la creación o el acondicionamiento de espacios públicos con valores naturales de gran valor ecológico; entre ellos, destacan el Parque del Agua "Luis Buñuel", las Riberas del Ebro, el Anillo Verde de Zaragoza, y el Camping Ciudad de Zaragoza, a los que se unen otros ya existentes anteriormente como el Parque Grande José Antonio Labordeta, el Canal Imperial de Aragón, la Arboleda de Macanaz, el Galacho de Juslibol, el Soto de Cantalobos y el Galacho de la Alfranca (Zaragoza Turismo, 2013b).

En cuanto a la oferta de alojamiento, la evolución de la oferta hotelera ha sido importante en la ciudad entre 2006 y 2012; en ese periodo, el número de hoteles ha crecido casi un 10\% (pasando de 91 a 101), lo que se ha traducido en un incremento de 3.463 plazas (INE, 2006-2012). La ciudad cuenta con buenas infraestructuras de comunicaciones, con un aeropuerto con algunas conexiones internacionales, y con una estación multimodal de gran capacidad. Su mayor potencial es su situación privilegiada en el centro del cuadrante norte peninsular, que le ha permitido ser un punto clave en la red ferroviaria peninsular al igual que en la red viaria española de carreteras. Según un informe de Exceltur realizado en 2012, la ciudad se encontraba en la cuarta posición entre las de mejor conectividad ferroviaria de alta velocidad (para trenes AVANT, ALVIA, AVE, ALARIS, ALTARIA y EUROMED), lo cual la posiciona estratégicamente para conexiones con otros mercados externos (Urbantur, 2013). El mismo informe indicaba que la Estación de Zaragoza-Delicias estaba situada en tercera posición (después de las de Madrid y Córdoba) como estación que más frecuencia de trenes de alta gama recibió en 2012. En resumen, la posición estratégica de la ciudad se ha visto claramente mejorada desde la llegada del AVE en 2002 (Pueyo, 2007). 
Una vez comentados algunos aspectos de la oferta turística de la ciudad, a continuación se tratan los relacionados con la demanda, para conocer aspectos como la evolución del número de turistas, su distribución a lo largo del año, o el uso que hacen de hoteles y de distintas formas de transporte.

El análisis de las pernoctaciones registradas en los hoteles de la ciudad permite analizar la evolución de la actividad turística, ya que es el tipo de alojamiento más utilizado por los turistas. Lo más llamativo de la evolución de las pernoctaciones registradas entre 2006 y 2012 (Gráfico 1) ha sido el aumento de las mismas en 2008 debido a la realización de la EXPO, y del descenso posterior con ligera y lenta recuperación de las cifras alcanzadas antes de ese año, sin duda, la evolución de la demanda posterior a 2008 ha estado muy influenciada por la situación de crisis económica existente en el país.

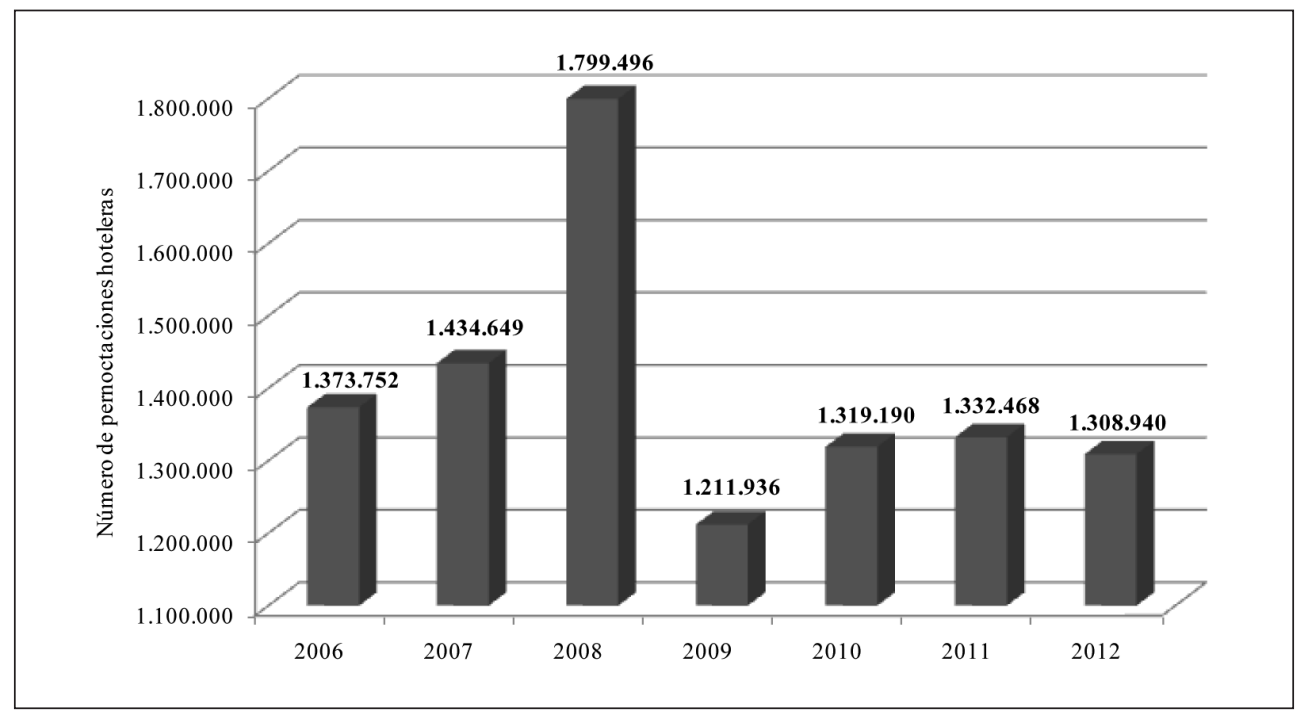

Gráfico 1. Evolución de las pernoctaciones hoteleras en la ciudad de Zaragoza, 2006-2012. Fuente: Encuesta de Ocupación Hotelera, INE, 2006-2012. Elaboración propia.

Sobre la distribución anual de esas pernoctaciones durante el mismo periodo de tiempo (2006-2012), los meses de enero y diciembre son los de menor demanda, (no superando las 100.000 en diciembre en ningún año de los analizados), mientras que octubre es el mes de mayor afluencia turística (INE, 2006-2012). De las pernoctaciones realizadas en hoteles, el mayor número corresponde a los turistas nacionales, mientras que entre los turistas no residentes en España, los franceses son los que ocupan la primera posición, seguidos por los italianos y portugueses (INE, 2006-2012). 
Conocer el tipo de transporte utilizado por los turistas para acceder a la ciudad de Zaragoza es el punto de partida para poder desarrollar indicadores de sostenibilidad de transporte y movilidad. Entre los distintos modos, y según datos procedentes de las encuestas realizadas por las Oficinas de Turismo de Zaragoza (Zaragoza Turismo, 2012), el medio de transporte más utilizado por parte de los turistas en 2012 fue el vehículo particular (Tabla 1), seguido del tren y el avión. Estos datos varían ligeramente cuando el motivo de la visita es por negocios, en cuyo caso se hace más uso del tren y del avión, y menos del vehículo propio. Sin embargo, el avión es cada vez menos utilizado por los turistas, por lo que el número de pasajeros en el aeropuerto de Zaragoza, sólo entre 2011 y 2012, cayó un 26\% (a 551.406 pasajeros en el 2012) (AENA, 2012). Este descenso se debe a la pérdida de conexiones aéreas, principalmente como consecuencia de un mayor uso del AVE.

Tabla 1. Medio de transporte utilizado por los visitantes para acceder a la ciudad de Zaragoza, 2012

\begin{tabular}{|l|c|c|}
\hline $\begin{array}{l}\text { Medio de } \\
\text { transporte }\end{array}$ & $\begin{array}{c}\text { \% medio de transporte utilizado } \\
\text { por los visitantes para } \\
\text { acceder a la ciudad }\end{array}$ & $\begin{array}{c}\text { \% medio de transporte utilizado } \\
\text { por los asistentes a eventos } \\
\text { de negocios }\end{array}$ \\
\hline Coche propio & 51 & 36,30 \\
Tren & 22 & 32,59 \\
Avión & 12 & 22,22 \\
Autobús & 12 & 8,15 \\
Coche alquilado & 3 & 0,74 \\
\hline
\end{tabular}

Fuente: Zaragoza Turismo, 2012. Elaboración propia.

Tras considerar algunos datos sobre la evolución de la oferta y la demanda, se aprecia que el número de alojamientos y de plazas ofertadas ha crecido en Zaragoza, aunque el número de turistas que recibe la ciudad descendió a partir de 2008 hasta situarse en niveles previos a la EXPO 2008. Si bien la planta hotelera y otros elementos del sistema turístico de la ciudad han mejorado claramente desde 2008, tales mejoras no se han visto acompañados por el mantenimiento de la demanda turística con motivo de la crisis económica. Actualmente, la ciudad compite con mejores estándares de calidad de vida debido a la mejora de sus infraestructuras y equipamientos, lo que la convierte en una ciudad con buena funcionalidad turística. Desde la EXPO 2008, Zaragoza cuenta con mejores recursos para competir a nivel tanto nacional como internacional en la atracción del turismo urbano y profesional. 
Ante el tímido repunte de algunas variables turísticas registradas desde 2012 (por ejemplo, el número total de turistas que visitan anualmente la ciudad) (Zaragoza Turismo, 2013a), y justificando el crecimiento que el turismo puede tener en el futuro, se hace necesario gestionar y controlar adecuadamente su evolución. Como en otros casos, dichas funciones se deberían realizar utilizando indicadores turísticos de sostenibilidad de carácter ambiental, con el fin de incorporar la dimensión ambiental a la actividad turística desarrollada en la ciudad. Por ejemplo, su uso podría ser útil para medir y controlar la estacionalidad o la concentración espacial del turismo, ya que son aspectos que ejercen, claramente, mucha presión en el medio ambiente. No obstante, las presiones más importantes se relacionan con la ocupación del suelo, con la congestión en la ciudad, con la generación de residuos urbanos, con el aumento de las emisiones procedentes del transporte, con el aumento del ruido o del consumo de agua, con el aumento de los vertidos de aguas residuales, o con la degradación del paisaje y la alteración de las zonas naturales de la ciudad al construirse determinadas instalaciones para uso turístico (De Esteban, 2008).

Tras aproximarnos a algunas características de la oferta y la demanda turística, las cuales deben tenerse en cuenta en el diseño de los indicadores, y enlazando con las experiencias puestas en marcha por otros organismos y municipios, a continuación se resumen el estado actual de utilización de indicadores de este tipo en el municipio de Zaragoza. Se trata de conocer con qué indicadores están trabajando actualmente los diferentes agentes y organismos públicos y privados en la ciudad.

\subsection{El desarrollo actual de indicadores de turismo en el municipio de Zaragoza}

Diferentes agentes y organismos trabajan por y para el turismo, y para la sostenibilidad del sector en la ciudad de Zaragoza. Entre ellos, destaca la Agencia de Medio Ambiente y Sostenibilidad del Ayuntamiento de Zaragoza, y en concreto a través de los indicadores recogidos en la Agenda 21 Local del municipio; además, también lo hacen el Observatorio Municipal de Estadística del Ayuntamiento, el Patronato de Turismo del Ayuntamiento, y la asociación Ebrópolis.

Entre los indicadores utilizados en el marco del desarrollo de la Agenda 21 Local, actualizados en 2012 (Ayuntamiento de Zaragoza, 2012) (Tabla 2) no hay ninguno cuya temática se relacione (directamente) con la sostenibilidad ambiental para el sector turístico. Sin embargo, algunos de los utilizados se podrían adaptar para su uso por parte del sector turístico, sin olvidar los problemas metodológicos y de medición que ello, en ocasiones, podría suponer. Por ejemplo, el indicador "Consumo final de energía" podría utilizarse para medir el consumo energético generado por la actividad turística; otro ejemplo sería el indicador de "Movilidad local", el cual se podría adaptar para medir, únicamente, la movilidad generada y desarrollada por los turistas. 
Tabla 2. Indicadores de sostenibilidad de la Agenda 21 Local de Zaragoza, 2012

\begin{tabular}{|c|c|c|}
\hline \multicolumn{3}{|c|}{ INDICADORES COMUNES EUROPEOS } \\
\hline Indicador & \multicolumn{2}{|l|}{ Evaluación } \\
\hline $\begin{array}{l}\text { Movilidad local y } \\
\text { transporte de pasajeros }\end{array}$ & \multicolumn{2}{|c|}{ Transporte diario de pasajeros, distancias y modos de transporte } \\
\hline $\begin{array}{l}\text { Disponibilidad de áreas } \\
\text { públicas abiertas y de } \\
\text { servicios locales básicos }\end{array}$ & \multicolumn{2}{|c|}{ Acceso a las áreas abiertas públicas y a otros servicios básicos } \\
\hline $\begin{array}{l}\text { Contribución local al } \\
\text { cambio climático global }\end{array}$ & \multicolumn{2}{|c|}{$\begin{array}{l}\text { Emisiones de } \mathrm{CO}_{2} \text { y otros gases de efecto invernadero } \\
\left(\mathrm{tCO}_{2} \text { /habitante) por sectores de actividad (agricultura, industrial, }\right. \\
\text { movilidad, residencial) }\end{array}$} \\
\hline Calidad aire local & \multicolumn{2}{|c|}{$\begin{array}{l}\text { Número de días en que se registra una buena calidad de aire } \\
\text { en cada uno de los contaminantes considerados en la ciudad } \\
\text { de Zaragoza }\end{array}$} \\
\hline $\begin{array}{l}\text { Utilización sostenible } \\
\text { del suelo }\end{array}$ & \multicolumn{2}{|c|}{$\begin{array}{l}\text { Desarrollo sostenible, recuperación y } \\
\text { protección el suelo y de los parajes del municipio }\end{array}$} \\
\hline Contaminación sonora & \multicolumn{2}{|c|}{$\begin{array}{l}\text { Población expuesta a niveles de ruido ambiental perjudiciales } \\
\text { tanto de día como de noche }\end{array}$} \\
\hline \multicolumn{3}{|c|}{ INDICADORES LOCALES ESPECÍFICOS } \\
\hline \multicolumn{2}{|c|}{ Indicador } & Evaluación \\
\hline Agua & Consumo total de agua & $\begin{array}{l}\text { Volumen de agua captada anualmente } \\
\text { para su potabilización ( } 1 / \text { hab.día). } \\
\text { Evalúa el grado de eficiencia en el } \\
\text { consumo de agua en la ciudad para } \\
\text { reducir su uso inadecuado }\end{array}$ \\
\hline \multirow[t]{2}{*}{ Residuos } & $\begin{array}{l}\text { Residuos urbanos } \\
\text { recogidos }\end{array}$ & $\begin{array}{l}\text { Pesaje de los residuos en la entrada } \\
\text { del CTRUZ (Centro de Tratamiento de } \\
\text { Residuos Urbanos de Zaragoza) (t/año) }\end{array}$ \\
\hline & $\begin{array}{l}\text { Residuos urbanos } \\
\text { recogidos selectivamente }\end{array}$ & $\begin{array}{l}\text { Pesaje de los residuos en la entrada } \\
\text { de los diferentes destinos: vidrio, } \\
\text { pilas, papel y envase ligero (t/año) }\end{array}$ \\
\hline Energía & Consumo final de energía & $\begin{array}{l}\text { Evolución del uso de los diferentes } \\
\text { tipos de consumo de energía: eléctrica, } \\
\text { combustibles líquidos, gas natural, } \\
\text { gases licuados del petróleo (tep/hab.año) }\end{array}$ \\
\hline
\end{tabular}




\begin{tabular}{|l|l|l|}
\hline \multicolumn{2}{|c|}{ INDICADORES LOCALES ESPECÍFICOS } \\
\hline Movilidad & Movilidad en bicicleta & $\begin{array}{l}\text { Evaluación } \\
\text { Ficador } \\
\text { Mide el no de metros de carriles-bicicleta }\end{array}$ \\
\hline Patrimonio natural & Naturaleza urbana & $\begin{array}{l}\text { Superficie de parques y jardines de la } \\
\text { ciudad (ha), integrando la naturaleza } \\
\text { en la ciudad y su área de influencia }\end{array}$ \\
\cline { 2 - 4 } & Zonas protegidas & $\begin{array}{l}\text { Inventario de las zonas protegidas del } \\
\text { municipio: \% sobre el término municipal } \\
\text { y según las diferentes figuras de } \\
\text { protección especial }\end{array}$ \\
\hline \multirow{2}{*}{ Globales } & Huella ecológica & $\begin{array}{l}\text { Superficie necesaria para producir los } \\
\text { recursos y asumir los residuos producidos } \\
\text { por la población del municipio de } \\
\text { Zaragoza }\end{array}$ \\
\cline { 2 - 4 } & $\begin{array}{l}\text { Agua y desarrollo } \\
\text { sostenible }\end{array}$ & $\begin{array}{l}\text { Relaciona el consumo de agua con el } \\
\text { número de habitantes, con las mejoras } \\
\text { de infraestructuras y con el PIB }\end{array}$ \\
\cline { 2 - 3 } & $\begin{array}{l}\text { Energía y desarrollo } \\
\text { sostenible }\end{array}$ & $\begin{array}{l}\text { Relaciona el consumo de energía con } \\
\text { el número de habitantes, con las } \\
\text { mejoras de infraestructuras y con el PIB }\end{array}$ \\
\cline { 2 - 3 } & Movilidad global & $\begin{array}{l}\text { Viajeros que utilizan el transporte } \\
\text { público, autobús, tranvía y cercanías }\end{array}$ \\
\hline
\end{tabular}

Fuente: Zaragoza Turismo, 2012. Elaboración propia.

También en el Observatorio Municipal de Estadística se trabajan algunos datos relativos al turismo (Tabla 3), y aunque ni son propiamente de carácter medioambiental y se centran en los viajeros en hoteles, se podrían aprovechar para medir la sostenibilidad ambiental del sector de cara a la confección de indicadores como el de capacidad de carga (turística) de la ciudad.

Respecto al Patronato Municipal de Turismo, publica anualmente informes con información turística y relacionada con la sostenibilidad medioambiental como, por ejemplo, el modo de transporte utilizado por los turistas para acceder a la ciudad,o los asistentes a distintos tipos de actos. Estos datos se obtienen de encuestas realizadas a los turistas en las Oficinas de Turismo y a los asistentes a eventos (congresos, ferias, etc.), y en la Tabla 4 se recogen algunos de los que se podrían utilizar para la puesta en marcha del sistema de indicadores. 
Tabla 3. Datos sobre turismo del Observatorio Municipal de Estadística del Ayuntamiento de Zaragoza, 2013

\begin{tabular}{|l|l|}
\hline Viajeros & $\begin{array}{l}\text { Viajeros en establecimientos hoteleros } \\
\text { Viajeros en establecimientos hoteleros: procedentes de España } \\
\text { Viajeros en establecimientos hoteleros: procedentes del extranjero }\end{array}$ \\
\hline Pernoctaciones & $\begin{array}{l}\text { Pernoctaciones en establecimientos hoteleros } \\
\text { Pernoctaciones en establecimientos hoteleros: procedentes de España } \\
\text { Pernoctaciones en establecimientos hoteleros: procedentes del extranjero }\end{array}$ \\
\hline Estancia media & Estancia media de los viajeros en establecimientos hoteleros \\
\hline Grado ocupación & $\begin{array}{l}\text { \% Habitaciones ocupadas } \\
\text { \% Plazas ocupadas }\end{array}$ \\
\hline
\end{tabular}

Fuente: Ayuntamiento de Zaragoza, 2013. Elaboración propia.

Por último, también en la Estrategia 2020 desarrollada por la asociación Ebrópolis (con la que colabora el Ayuntamiento), se presentan indicadores de sostenibilidad turística, aunque tampoco son de carácter medioambiental (EBRÓPOLIS, 2008-2013). Son indicadores que se relacionan con los ejes estratégicos en los que se divide la Estrategia 2020. Es dentro del eje estratégico de "Zaragoza, Ciudad de Alianzas", en el que se encuentran los indicadores propiamente aplicables al sector turístico (Tabla 5), pero no hay ninguno referido a la medición de la sostenibilidad ambiental turística de la ciudad. En esta Tabla 5 se recogen los indicadores aplicables al sector turístico y los que no son de carácter turístico, aunque como se ha indicado en el caso de la Agenda 21 Local, se pueden obtener datos y poder asociarlos a indicadores para la sostenibilidad del turismo.

A la vista de lo anterior, se puede afirmar que la ciudad de Zaragoza posee un cierto déficit en cuanto al tratamiento que en ella se hace de la información turística enfocada hacia la sostenibilidad ambiental, y que no tiene establecido un sistema de indicadores ambientales para el turismo. Por esta razón, se podrían incluir primeramente algunos indicadores de este tipo en la Agenda 21 Local, respondiendo, tal y como muestra la evolución de la oferta y demanda en la ciudad de Zaragoza, a la gran funcionalidad turística de la ciudad. Asimismo, y como medida para que Zaragoza se siga consolidando como ciudad sostenible, se deberían incluir indicadores de sostenibilidad ambiental en el ámbito del turismo en la Estrategia 2020.

La propuesta de indicadores que aquí se realiza también incluye la creación de un Observatorio de Turismo en Zaragoza, ya que como en otras de tamaño similar o mayor, podría concentrar funciones para realizar una mejor evaluación y control de la evo- 
Tabla 4. Datos sobre turismo del Informe Anual de Turismo, 2012

\begin{tabular}{|c|c|}
\hline \multicolumn{2}{|c|}{ DATOS DE TURISMO } \\
\hline $\begin{array}{l}\text { Datos de la oferta y de la demanda } \\
\text { del municipio de Zaragoza }\end{array}$ & $\begin{array}{l}\text { Capacidad hotelera } \\
\text { Grados de ocupación hotelera } \\
\text { Estancia media } \\
\text { Viajeros } \\
\text { Pernoctaciones } \\
\text { Motivación del viaje } \\
\text { Información solicitada } \\
\text { Procedencia de los turistas nacionales } \\
\text { Procedencia turistas extranjeros } \\
\text { Días de estancia } \\
\text { Tipo de alojamiento } \\
\text { Medio de transporte utilizado: coche propio, tren, } \\
\text { avión, autobús, coche de alquiler }\end{array}$ \\
\hline $\begin{array}{l}\text { Programas y servicios de } \\
\text { Zaragoza Turismo }\end{array}$ & $\begin{array}{l}\text { Participantes en las visitas guiadas: paseos } \\
\text { guiados y Bizi Tour } \\
\text { Participantes en el Bus Turístico: diurno, } \\
\text { megabús, nocturno }\end{array}$ \\
\hline Prestación servicios congresos & $\begin{array}{l}\text { Número de asistentes a los diferentes eventos } \\
\text { congresos realizados en la ciudad } \\
\text { Número de congresos realizados } \\
\text { Medio de transporte utilizado para llegar a la } \\
\text { ciudad por parte de los asistentes a congresos }\end{array}$ \\
\hline $\begin{array}{l}\text { Prestación servicios eventos: congresos, } \\
\text { jornadas, convenciones, reuniones y } \\
\text { otros eventos (ferias, exposiciones, etc.) }\end{array}$ & $\begin{array}{l}\text { Número de asistentes dependiendo del tipo de } \\
\text { evento realizado, y número total de asistentes a } \\
\text { todos los eventos } \\
\text { Número de eventos realizados en la ciudad } \\
\text { Número de eventos mensuales }\end{array}$ \\
\hline
\end{tabular}

Fuente: Zaragoza Turismo, 2012. Elaboración propia.

lución de las cuestiones ambientales ligadas al turismo; además, el funcionamiento de este Observatorio Turístico permitiría mejorar la coordinación de la actividad turística con el resto de actividades en el municipio, pudiéndose disponer de más y mejor información sobre la evaluación de variables turísticas. 
Tabla 5. Indicadores de la Estrategia 2020 de Ebrópolis

\begin{tabular}{|c|c|c|}
\hline Eje Estratégico & Indicador & Evolución \\
\hline \multirow[t]{2}{*}{$\begin{array}{l}\text { Zaragoza, Ciudad } \\
\text { de Alianzas }\end{array}$} & Número de pernoctaciones & $\begin{array}{l}\text { Volumen de pernoctaciones en la } \\
\text { provincia y en la ciudad de } \\
\text { Zaragoza }\end{array}$ \\
\hline & Tiempo medio de estancia & $\begin{array}{l}\text { Estancia media en la provincia y } \\
\text { ciudad de Zaragoza en comparación } \\
\text { con la media española }\end{array}$ \\
\hline \multirow[t]{5}{*}{$\begin{array}{l}\text { Zaragoza, Ciudad } \\
\text { de Alianzas }\end{array}$} & $\begin{array}{l}\text { Indice de ocupación } \\
\text { hotelera media }\end{array}$ & $\begin{array}{l}\text { Índice de ocupación hotelera por } \\
\text { plazas en Zaragoza ciudad y } \\
\text { Zaragoza provincia en relación } \\
\text { con la media española }\end{array}$ \\
\hline & $\begin{array}{l}\text { Número de eventos } \\
\text { realizados en Zaragoza }\end{array}$ & $\begin{array}{l}\text { Número de eventos realizados en la } \\
\text { ciudad de Zaragoza }\end{array}$ \\
\hline & $\begin{array}{l}\text { Transporte público de } \\
\text { viajeros }\end{array}$ & $\begin{array}{l}\text { Mide el número de viajes en } \\
\text { trasporte público por habitante y } \\
\text { año en la ciudad }\end{array}$ \\
\hline & Kilómetros de carril bici & $\begin{array}{l}\text { Evolución del número de Kilómetros } \\
\text { de carril bici existentes en la ciudad }\end{array}$ \\
\hline & $\begin{array}{l}\text { Nivel de satisfacción de } \\
\text { los servicios públicos } \\
\text { de transporte disponibles }\end{array}$ & $\begin{array}{l}\text { Porcentaje de personas que se } \\
\text { declaran satisfechas con el nivel } \\
\text { de los servicios públicos de } \\
\text { transporte }\end{array}$ \\
\hline \multirow[t]{5}{*}{$\begin{array}{l}\text { Zaragoza, Ciudad } \\
\text { Sostenible }\end{array}$} & Emisión de $\mathrm{CO}_{2}$ & $\begin{array}{l}\text { Emisión de } \mathrm{CO}_{2} \text { en Zaragoza } \\
\text { (toneladas/habitante/año) }\end{array}$ \\
\hline & Consumo final de energía & $\begin{array}{l}\text { Consumo anual de energía por } \\
\text { habitante en Zaragoza ciudad }\end{array}$ \\
\hline & $\begin{array}{l}\text { Calidad del aire en la } \\
\text { localidad }\end{array}$ & $\begin{array}{l}\text { Número de días al año con buena } \\
\text { calidad del aire en cada uno de los } \\
\text { contaminantes considerados, en la } \\
\text { ciudad de Zaragoza }\end{array}$ \\
\hline & $\begin{array}{l}\text { Residuos urbanos recogidos } \\
\text { selectivamente }\end{array}$ & $\begin{array}{l}\text { Ratio de recogida selectiva por } \\
\text { habitante y año de papel, vidrio y } \\
\text { envases ligeros }\end{array}$ \\
\hline & $\begin{array}{l}\text { Satisfacción con la calidad } \\
\text { y cantidad de espacios } \\
\text { naturales }\end{array}$ & $\begin{array}{l}\text { Porcentaje de personas que se } \\
\text { declaran satisfechas con la calidad } \\
\text { y cantidad de los espacios naturales }\end{array}$ \\
\hline
\end{tabular}

Fuente: Ebrópolis, 2008-2013. Elaboración propia. 


\section{Propuesta de indicadores para un turismo sostenible en el municipio de Zaragoza}

Como suele ser habitual, la respuesta eficiente al reto de la sostenibilidad turística en el ámbito municipal requiere, por un lado, de un fuerte compromiso social, e involucrar a todos los sectores sociales con un espíritu de responsabilidad compartida, aunque diferenciada según se trate de instituciones, empresas, organizaciones no gubernamentales, individuos, etc.; por otro lado, también implica "repensar" el conjunto de instrumentos y mecanismos de gestión actuales para incentivar cambios significativos en las actuales prácticas turísticas, teniendo en cuenta que es necesario reestructurar los modos de producción, distribución y consumo (Pulido y Sánchez, 2007).

La propuesta consta de un total de 40 indicadores ambientales (Tabla 6), los cuales se dividen en dos tipos, según se refieran a la actividad turística o a los temas ambientales; esta doble tipología responde a las características de la zonas de estudio, por un lado, urbana, y afectada por la actividad turística, aunque también afectada por otras actividades humanas asociadas. Además, en la Tabla 6 se presentan esos indicadores clasificados en 13 temáticas, que son las habituales utilizadas por los organismos e iniciativas en sus propuestas para un turismo sostenible. Los 40 indicadores propuestos se han generado considerando los siguientes criterios:

- Que sean relevantes para conocer el medio ambiente de la ciudad de Zaragoza desde la perspectiva turística.

- Que los datos para su construcción estén disponibles y sean fáciles de obtener de instituciones, asociaciones, organismos, etc.

- Que puedan ser actualizados con regularidad.

- Que sean de fácil interpretación.

En la propuesta, los indicadores se clasifican según el Modelo PER (Presión-EstadoRespuesta), basado en la metodología de la OCDE (2003), y que según la Federación Española de Municipios y Provincias (FEMP, 2002), significa:

- Presión: son los indicadores que describen las presiones ejercidas por las actividades humanas sobre el medio ambiente.

- Estado: son indicadores que reflejan la calidad del medio ambiente y los aspectos cualitativos y cuantitativos de los recursos ambientales (agua, aire, etc.). Dan una visión del medio ambiente y su evolución.

- Respuesta: son indicadores que miden cómo la sociedad responde ante los cambios ambientales. Son las acciones individuales y colectivas con las que se quieren paliar las repercusiones negativas sobre el medio ambiente que tienen las actividades humanas. 
Tabla 6. Tipologías e indicadores de turismo propuestos para el municipio de Zaragoza

\begin{tabular}{|c|c|}
\hline \multicolumn{2}{|r|}{ TEMÁTICA 1. TENDENCIA DEL TURISMO } \\
\hline I.1. & $\begin{array}{l}\text { Presión humana: medir la densidad de población, incluyendo la presencia máxima } \\
\text { de turistas. }\end{array}$ \\
\hline I.2. & $\begin{array}{l}\text { Población Turística Equivalente del municipio (PTE): a cuántas personas (que residie- } \\
\text { sen todo el año en el municipio) equivalen las pernoctaciones registradas en la Encuesta } \\
\text { de Ocupación Hotelera del INE. }\end{array}$ \\
\hline I.3. & Población Turística Equivalente del municipio en relación a la población residente. \\
\hline I.4. & $\begin{array}{l}\text { Volumen de turistas en la ciudad en distintos periodos de tiempo (de máxima y menor } \\
\text { demanda) }\end{array}$ \\
\hline I.5. & Relación visitantes/Población residente. \\
\hline I.6. & $\begin{array}{l}\text { Índice Espacial de Frecuentación Turística: densidad de turistas en espacios y fechas con- } \\
\text { cretas. }\end{array}$ \\
\hline I.7. & $\begin{array}{l}\text { Tasa de Función Turística: porcentaje entre el número de camas turísticas disponibles } \\
\text { y la población residente. }\end{array}$ \\
\hline I.8. & Número de camas en hoteles y establecimientos similares por cada 1.000 habitantes. \\
\hline I.9. & Número de pernoctaciones realizadas por los turistas en diferentes tipos de alojamiento. \\
\hline \multicolumn{2}{|r|}{ TEMÁTICA 2. INFRAESTRUCTURAS TURÍSTICAS } \\
\hline I.10. & $\begin{array}{l}\text { Número de construcciones dedicadas al sector turístico que se encuentran en desuso } \\
\text { tanto desde el sector turístico privado como público (palacio de congresos, alojamien- } \\
\text { tos turísticos, edificios dedicados a actos turísticos, etc.). }\end{array}$ \\
\hline \multicolumn{2}{|r|}{ TEMÁTICA 3. TRANSPORTE Y MOVILIDAD } \\
\hline I.11. & Llegadas turísticas según el modo de transporte y según lugar de procedencia. \\
\hline I.12. & $\begin{array}{l}\text { Número y longitud de recorridos acondicionados para los peatones, los autobuses y las } \\
\text { bicicletas. }\end{array}$ \\
\hline I.13. & $\begin{array}{l}\text { Densidad de vehículos en el núcleo urbano en diferentes fechas de distinta afluencia } \\
\text { turística. }\end{array}$ \\
\hline I.14. & $\begin{array}{l}\text { Existencia de transporte público (número de autobuses y tranvías) entre estación de tren, } \\
\text { de autobuses y del aeropuerto, y las zonas de mayor afluencia turística. }\end{array}$ \\
\hline \multicolumn{2}{|r|}{ TEMÁTICA 4. RUIDO } \\
\hline I.15. & $\begin{array}{l}\text { Nivel de contaminación acústica: medición de los niveles de contaminación acústica } \\
\text { diurna y nocturna debido al tráfico rodado para describir los niveles de presión, potencia } \\
\text { o intensidad sonora en épocas de mayor afluencia turística en el municipio. }\end{array}$ \\
\hline
\end{tabular}




\begin{tabular}{|c|c|}
\hline I.16. & $\begin{array}{l}\text { Análisis de las fuentes emisoras de ruido debido al sector turístico en la época de ma- } \\
\text { yor afluencia de turismo. }\end{array}$ \\
\hline \multicolumn{2}{|r|}{ TEMÁTICA 5. AIRE } \\
\hline I.17. & $\begin{array}{l}\text { Estimaciones sobre las emisiones de } \mathrm{CO}_{2} \text { (aire acondicionado, calefacción, electricidad, } \\
\text { etc.) con origen en las principales infraestructuras turísticas como oficinas de turismo, } \\
\text { edificios culturales, museos o palacios de congresos. Los factores de emisión de } \mathrm{CO}_{2} \\
\text { dentro de estas infraestructuras pueden ser por la utilización de gas natural, fuelóleo, } \\
\text { gasóleo, GLP genérico, propano y butano o por la luz. Se aplicarían los factores de emi- } \\
\text { sión derivados del informe del Inventario Nacional de Emisiones le Ministerio de Agri- } \\
\text { cultura y Alimentación y Medio Ambiente (2012) a partir de la energía utilizada en las } \\
\text { infraestructuras descritas. }\end{array}$ \\
\hline I.18. & $\begin{array}{l}\text { Emisiones de } \mathrm{CO}_{2} \text { /día por turista alojado en un establecimiento reglado. Aplicación de } \\
\text { los factores de emisión derivados del informe del Inventario Nacional de Emisiones del } \\
\text { Ministerio de Agricultura y Alimentación y Medio Ambiente (2012) para calcular las emi- } \\
\text { siones de } \mathrm{CO}_{2} \text { al día/ turistas en alojamiento reglado, a partir del consumo de gas na- } \\
\text { tural, fuelóleo, gasóleo, GLP genérico, propano y butano o por la luz que se realiza en } \\
\text { cada establecimiento. }\end{array}$ \\
\hline \multicolumn{2}{|r|}{ TEMÁTICA 6. ENERGÍA } \\
\hline I.19. & $\begin{array}{l}\text { Cuantificar la cantidad media de consumo de gas natural y electricidad en los estable- } \\
\text { cimientos de alojamiento y en los servicios públicos del sector turístico (museos, pala- } \\
\text { cio de congresos, etc.) por turista y día. }\end{array}$ \\
\hline \multicolumn{2}{|r|}{ TEMÁTICA 7. CONSUMO DE AGUA } \\
\hline I.20. & $\begin{array}{l}\text { Demanda hídrica de los turistas por día, en relación al uso del agua de la población re- } \\
\text { sidente. }\end{array}$ \\
\hline \multicolumn{2}{|r|}{ TEMÁTICA 8. AGUAS RESIDUALES } \\
\hline I.21. & $\begin{array}{l}\text { Generación de aguas residuales por el turismo, a partir del volumen de turistas y del } \\
\text { número de pernoctaciones totales al año. }\end{array}$ \\
\hline \multicolumn{2}{|r|}{ TEMÁTICA 9. RESIDUOS SÓLIDOS URBANOS } \\
\hline I. 22 & $\begin{array}{l}\text { Generación total de residuos sólidos urbanos por parte de los turistas, utilizando el nú- } \\
\text { mero de pernoctaciones totales al año. }\end{array}$ \\
\hline I.23. & Cálculo de residuos domésticos municipales por turista en temporada alta. \\
\hline I.24. & Generación de basuras en las principales zonas turísticas. \\
\hline \multicolumn{2}{|r|}{ TEMÁTICA 10. USO DEL SUPERFICIE MUNICIPAL } \\
\hline I.25. & Áreas cubiertas por zonas verdes y parques en el municipio. \\
\hline
\end{tabular}




\begin{tabular}{|c|c|}
\hline \multicolumn{2}{|r|}{ TEMÁTICA 11. INFORMACIÓN/INSTRUMENTOS SOCIALES } \\
\hline I.26. & $\begin{array}{l}\text { Percepción de la población local sobre el papel del turismo en la promoción y recu- } \\
\text { peración de espacios naturales en la ciudad. }\end{array}$ \\
\hline I.27. & $\begin{array}{l}\text { Percepción de la población local sobre si el número de contenedores del municipio es } \\
\text { suficiente para atender a la población local y los turistas (en temporada alta). }\end{array}$ \\
\hline I.28. & $\begin{array}{l}\text { Valoración de los turistas sobre la limpieza de calles y lugares públicos en distintos pun- } \\
\text { tos de la ciudad. }\end{array}$ \\
\hline I.39. & $\begin{array}{l}\text { Percepción de la población local sobre si la congestión del tráfico en el municipio es } \\
\text { ocasionada por el turismo. }\end{array}$ \\
\hline I. 30 . & $\begin{array}{l}\text { Valoración por parte los turistas de la congestión del tráfico en puntos concretos de la } \\
\text { ciudad. }\end{array}$ \\
\hline I.31. & $\begin{array}{l}\text { Percepción de la población local sobre si el entorno del municipio ha empeorado con } \\
\text { el desarrollo turístico. }\end{array}$ \\
\hline I.32. & Valoración de los turistas de la accesibilidad a lugares de interés turístico. \\
\hline I.33. & Satisfacción turística con la ciudad como destino turístico. \\
\hline \multicolumn{2}{|r|}{$\begin{array}{l}\text { TEMÁTICA 12. DOCUMENTACIÓN SOBRE LA ESTRUCTURA } \\
\text { FUNCIONAL DEL MEDIOAMBIENTE MUNICIPAL }\end{array}$} \\
\hline I.34. & Diversificación del producto turístico. \\
\hline I.35. & Capacidad de gestión de la autoridad local en turismo. \\
\hline I.36. & Control de acceso a sitios de interés turístico. \\
\hline I. 37. & $\begin{array}{l}\text { Incentivación a las empresas turísticas a que introduzcan procesos de mejora me- } \\
\text { dioambientales. }\end{array}$ \\
\hline I. 38 . & Educación medioambiental en el municipio. \\
\hline I.39. & $\begin{array}{l}\text { Número de indicadores de la Agenda } 21 \text { Local de Zaragoza que incluyan elementos de } \\
\text { turismo sostenible. }\end{array}$ \\
\hline \multicolumn{2}{|r|}{ TEMÁTICA 13. INSTRUMENTOS REGULATORIOS } \\
\hline I. 40 . & $\begin{array}{l}\text { Número de empresas turísticas que participan en programas ambientales reconocidos } \\
\text { (Sistemas de Gestión Ambiental). }\end{array}$ \\
\hline
\end{tabular}

Fuente: Elaboración propia.

Cada indicador es presentado en una ficha estándar con el objetivo de homogeneizar los datos correspondientes a cada indicador y poder ofrecer la información de forma eficiente. A su vez, cada ficha incluye varios apartados, que recogen los siguientes aspectos: 
- el carácter del indicador (Presión "P", Estado "E”, Respuesta "R"),

- la descripción del indicador,

- el objetivo del indicador,

- la fórmula para su cálculo,

- la interpretación y explicación de la fórmula,

- sección del Ayuntamiento responsable de su mantenimiento,

- por último, la periodicidad de muestreo para hacer un seguimiento de la evolución del indicador.

Todos los indicadores propuestos, con sus respectivas fichas, han sido realizados a partir de información extraída de indicadores para un turismo sostenible utilizados por otros organismos nacionales e internacionales, si bien han sido adaptados posteriormente a la situación, fuentes disponibles y medios existentes en la ciudad de Zaragoza.

Esta propuesta de indicadores de sostenibilidad está relacionada con la creación, también, de un Observatorio Turístico, desde el que se haría el seguimiento y control de los mismos. Zaragoza no cuenta con tal observatorio (sí con uno de Estadística), pero sería una iniciativa deseable para establecer lazos de coordinación entre los distintos niveles de la Administración pública (local -Diputación Provincial de Zaragoza y Ayuntamiento-, pero también regional) y las empresas del sector. Obviamente, la creación de un Observatorio de Turismo excedería las funciones de desarrollo, control y seguimiento de los indicadores, por lo que sería una buena oportunidad para aglutinar funciones ahora inexistentes o dispersas como ser el punto de contacto de todos los agentes públicos y privados, apoyar a las empresas del sector para aumentar su volumen de negocio, sistematizar mucha información necesaria para la competitividad del sector y para la toma de decisiones sobre el sector. También deberían ser funciones del Observatorio fomentar tareas de investigaciones y para el conocimiento del sector, además de la transferencia de tecnología y conocimiento entre el sector empresarial y el turísitico (Palafox y Segrado, 2008).

Funciones parecidas a las que podría concentrar este Observatorio las desarrollan actualmente en otras ciudades organismos, normalmente autónomos, de capital público (con o sin participacion privada) o de capital mixto, desarrollados bajo diversas formulas juridicas (consorcios, empresas publicas municipales, fundaciones, patronatos municipales de turismo...). Este tipo de entidades se pueden encontrar en ciudades como Santiago de Compostela (Turismo de Santiago_INCOLSA, S.A.), Cordoba (Consorcio de Turismo de Cordoba), Salamanca (Turismo y Comunicacion de Salamanca, S.A.U.), Cuenca (Fundacion Turismo de Cuenca), Segovia (Gestion y Calidad Turistica Ciudad de Segovia S.A.U.), Tarragona (Patronato Municipal de Turismo) y Toledo (Patronato Municipal de Turismo) (García, 2007). Cualquiera de estas fórmulas podría debatirse para el caso de Zaragoza. 


\subsection{Fases de implantación de los indicadores e información requerida}

Puesto que la ciudad de Zaragoza no cuenta con un sistema propiamente dicho de indicadores de sostenibilidad ambiental para el turismo, y como ha sido habitual en otros procesos de implantación (Ivars, 2001), convendría comenzar aplicando los más básicos y los que menor dificultad, medios e información requieren, en función de su eficiencia y utilidad. Así pues, en una primera fase se podrían desarrollar los relacionados a continuación (según la numeración de la Tabla 6), y que abarcan las trece temáticas en las que se han clasificado:

I.2. Población Turística Equivalente del municipio (PTE).

I.6. Índice Espacial de Frecuentación Turística.

I.7. Tasa de Función Turística.

I.9. Número de noches pasadas por los turistas en diferentes tipos de acomodación.

I.11. Llegadas turísticas según el modo de transporte y según lugar de procedencia.

I.12. Número y longitud de recorridos que se hayan acondicionado para los peatones, los autobuses y las bicicletas.

I.17. Estimaciones sobre las emisiones de $\mathrm{CO}_{2}$.

I.19. Cuantificar la cantidad media de consumo de gas natural y electricidad en los establecimientos de alojamiento y en los servicios públicos de turismo.

I.20. Demanda hídrica de los turistas por día.

I.22. Generación total de residuos sólidos urbanos por parte de los turistas.

I.27. Percepción de la población local sobre si el número de contenedores del municipio es suficiente para atender a la población local y los turistas (en temporada alta).

I.28. Valoración de los turistas sobre la limpieza de calles y lugares públicos en el destino turístico.

I.32. Valoración de los turistas de la accesibilidad al destino.

I.37. Incentivación a las empresas turísticas a que introduzcan procesos de mejora medioambientales.

I.40. Número de empresas turísticas que participan en programas ambientales reconocidos (Sistemas de Gestión Ambiental).

Estos 15 indicadores se podrían aplicar durante un periodo de tiempo de prueba (alrededor de 5 años), para posteriormente evaluar su eficacia y determinar si deben ser complementados con otros de los indicadores propuestos. 
La información necesaria para completar los indicadores se podría obtener de estadísticas gestionadas por el Instituto de Estudios Turísticos (IET, actualmente perteneciente al Ministerio de Industria, Energía y Turismo) y por Instituto Nacional de Estadística (INE); por ejemplo, el IET ofrece los Movimientos Turísticos de los Españoles (FAMILITUR), y el INE diversas Encuestas de Ocupación según tipos de alojamientos, o el Censo de la Población y la Vivienda, cuyos datos serían de utilidad para el mantenimiento de algunos de los índices propuestos. También el Gobierno de Aragón (Dirección General de Turismo) edita la Guía de Servicios Turísticos de Aragón, con información sobre tipos de alojamientos y su capacidad.

Sin embargo, las estadísticas publicadas por estos organismos serían insuficientes, por lo que deberían ser completadas con otra información ofrecida a escala local-municipal o incuso provincial. Por ejemplo, la información más específica y relativa a infraestructuras, o ligada al consumo de recursos, sería más difícil de obtener, por lo que el Ayuntamiento debería desarrollar un programa de colaboración con empresas públicas y privadas, para obtener y facilitar esa información que debería crearse ex novo; también para acceder a datos sobre el consumo de recursos energéticos (agua, electricidad, gas...) en determinados alojamientos o infraestructuras turísticas, el Ayuntamiento debería crear un sistema o programa para unificar dicha información, al igual que implementar algún sistema para medir la generación de residuos en diversos tipos de instalaciones (públicos y privados, pero del ámbito del turismo). La información necesaria para la valoración de los turistas de aspectos de limpieza o accesibilidad en la ciudad procedería de encuestas que ya se realizan actualmente a turistas, aunque se tendría que revisar el objetivo de las mismas, cómo se realizan y qué se pregunta en ellas, para coordinar la información obtenida con el nuevo sistema de indicadores. La cuantificación del sistema de indicadores debería conllevar la construcción de una base de datos gestionada desde el Ayuntamiento, de forma similar a la creada en otras ciudades (Pérez et al., 2009).

\section{Conclusiones}

Según la OMT (2005), y entre otros factores, la competitividad de los destinos turísticos dependerá de su capacidad para definir un modelo turístico competitivo, siempre y cuando esté basado en criterios de sostenibilidad, que permita asegurar la continuidad de los recursos y la satisfacción de la población residente y los turistas (Pulido y Sánchez, 2007). Por ello, el reto de la sostenibilidad en turismo requiere consensos importantes entre los diversos sectores implicados, instituciones, empresas, e incluso la población residente y los turistas. La implantación de un sistema de indicadores sería sólo una parte de la nueva política turística requerida, del conjunto de mecanismos e instrumentos de gestión de la práctica turística.

Actualmente, se asiste a un reforzamiento de la política turística a escala local, visible en municipios de diferente entidad urbana e incluso de diferente perfil turístico. De 
hecho, se aprecia un cambio importante en el papel de los gobiernos locales, para los que el turismo, como hecho socioeconómico, adquiere un gran protagonismo. Una de las realidades que se manifiesta con más claridad es el peso político que la sostenibilidad ha adquirido en los nuevos planteamientos de planificación, además de en el desarrollo de metodología e instrumentos de análisis y evaluación (Pulido y Sánchez, 2007). En este sentido, un uso valioso de los indicadores y de la verificación asociada seria permitirían a un destino comprobar y comparar su estado de sostenibilidad con otros destinos, lo cual podría ayudar a mostrar los aspectos de debilidad a los que habría que dar prioridad; pero para que los destinos cooperen sería necesario desarrollar indicadores y procesos de verificación similares (PNUMA-OMT, 2006).

Una cuestión importante es que frente al gran desarrollo de metodologías y herramientas para medir la sostenibilidad en turismo y su aplicación en distintos territorios, falta analizar los resultados de esa aplicación, sobre todo comparativamente, para establecer relaciones entre los diversos indicadores que integran cada metodología (Ibáñez y Ángeles, 2012). En la misma línea, la OMT indica que, si bien la necesidad de puesta en marcha de nuevos instrumentos de gestión para la sostenibilidad están ampliamente aceptados y son vistos como necesarios, la aplicación efectiva por parte de los gobiernos (centrales, regionales y locales) ha sido lenta y parcial (Yunis, 2003). Con ello, parece que el turismo sostenible se enfrenta al problema de la gran distancia existente entre las orientaciones metodológicas y el conocimiento teórico, y su aplicación práctica en la planificación real (Pulido y Sanchez, 2007).

Una de las críticas usuales a los distintos sistemas de indicadores es que están pensados para su aplicación en espacios amplios o a escala regional o nacional, por lo que dejan de ser útiles a escala local cuando entran en juego las particularidades sociales, económicas y culturales. Al mismo tiempo, su aplicación adolece de una visión multidisciplinaria y sistémica que tome en cuenta las relaciones entre los diversos elementos que intervienen dentro de esta actividad. Finalmente, se debería hacer hincapié en la necesidad de generar nuevos modelos se sostenibilidad turística, en los que se reestructuren, recombinen, mejoren, adapten e incorporen nuevos criterios, lo cual permitiría la incorporación de indicadores más apegados a la realidad local, además de que proporcionarían una idea mucho más certera del balance obtenido como resultado de la integración de los impactos negativos y positivos de esta actividad (Ibánez y Ángeles, 2012). Evidentemente, esto tiene que ver con que es imprescindible un acuerdo entre los investigadores de la realidad turística sobre determinados mínimos que deben conocerse y valorarse en la trayectoria de los diferentes destinos, con el fin de realizar un seguimiento de los mismos y poder prever posibles impactos negativos que conduzcan al deterioro general de la propia disciplina turística.

Otra crítica a los sistemas de indicadores actuales es que la mayor parte de las propuestas realizadas hasta ahora son para evaluar de forma independiente los diferentes componentes de la sostenibilidad, en lugar de para medir el caracter integral y multi- 
dimensional de los procesos de desarrollo en sus vertientes ambiental, social, económica y cultural (Bermejo y Nebreda, 1998). Tal dificultad debería obligar a la creacion de sistemas de indicadores adaptados a la especificidad de cada territorio, distinguiendo entre los distintos tipos de espacios turisticos, su grado de desarrollo y otras circunstancias que influyen tanto en la evolucion de la actividad turistica como en su orientacion hacia el desarrollo sostenible (Ivars, 2001).

En la revisión de experiencias, a escala municipal se ha identificado la carencia de información turística desde el punto ambiental, lo cual constituye un factor limitante a la hora de aplicar indicadores de sostenibilidad en turismo. Todas las organizaciones e iniciativas tanto a nivel internacional como nacional tratan los datos de tendencia sobre el número de personas que atraviesan las fronteras, llegada de turistas y los días de alojamiento de éstos en establecimientos hoteleros, pero hace falta desarrollar información que recoja datos pertinentes sobre el impacto ambiental como emisiones a la atmósfera, producción de residuos de las actividades turísticas, o mediciones del impacto ambiental del turismo tales como presión que debe soportar un destino turístico. Pero a ello también se le ha de sumar la dificultad de poder aislar el impacto directo en el medio ambiente de la actividad turística sobre otras que se desarrollan sobre el mismo espacio de destino, como por ejemplo con la medición de emisiones a la atmósfera derivadas de la actividad turística.

Otra de las conclusiones tiene que ver la necesidad de armonizar y poner en común el ya gran número de indicadores sobre sostenibilidad, y en concreto los relacionados con el turismo, debido a la gran dispersión y dificultad para aplicarlos en espacios concretos. Como se ha señalado, es cierto que esa diversidad responde a la diversidad de problemas existentes en cada destino, a que en todos no se puede acceder al mismo tipo de información, y a que los indicadores no se aplican siempre a la misma escala territorial. Sin embargo, convendría que los organismos e instituciones pusieran en común los distintos sistemas de indicadores, de forma similar a lo que ocurre para la aplicación de las Agendas 21, al disponerse de unos indicadores comunes (europeos) y otros locales adaptados a la realidad local. Pero no sólo armonizar los indicacores, sino también las escalas y los valores/resultados, con el fin de permitir las comparaciones entre lugares diferentes.

Finalmente, señalar que la Administración Local en Zaragoza no ha puesto en marcha un sistema de indicadores para la sostenibilidad ambiental del sector turístico, a pesar de ser una de las ciudades españolas que recibe un elevado número de turistas y de que ha aumentado su oferta y demanda turística. Por esta razón, y siguiendo el ejemplo de otras ciudades de tamaño medio y de parecida vocación turística, parece necesario poner en marcha algún sistema de indicadores de sostenibilidad ambiental para controlar el estado y evolución de variables turísticas, fijando así las bases para el crecimiento sostenible del sector, y para velar por la conservación de los recursos naturales, ambientales y energéticos de la ciudad y su entorno. 
En cuanto a la creación del Observatorio de Turismo es una tendencia internacional y nacional que, en el caso de Zaragoza, brindaría la oportunidad de generar, concentrar y transmitir información, necesaria para la toma de decisiones, pero también de gran importancia para la mejora del negocio y de la competitividad del sector en la ciudad. Sin embargo, esta propuesta, relacionada con la creación del sistema de indicadores, debería concitar el acuerdo entre los diversos niveles institucionales y las empresas implicadas.

\section{Bibliografía}

AENA, 2012. Estadísticas tráfico. Tráfico de pasajeros, operaciones y carga en los aeropuertos españoles. Madrid: AENA y Gobierno de España. En línea [Acceso: 09/05/2014]: http://www. aena-aeropuertos.es/csee/Satellite?pagename=Estadisticas/Home

Agència d' Ecologia Urbana de Barcelona, 2010. Sistema de indicadores y condicionantes para ciudades grandes y medianas. Barcelona: Ed. Ministerio de Medio Ambiente, y Medio Rural y Marino. 81 págs. En línea [Acceso: 31-01-2014]: http://www.ecourbano.es/imag/pdf/INDICADORES\%20CIUDADES\%20GRANDES\%20Y\%20MEDIANAS.pdf

Alonso, Ma P. y Bellet, C., 2009. El tren de alta velocidad y el proyecto urbano. Un nuevo ferrocarril para la Zaragoza del tercer milenio. Scripta Nova. Revista Electrónica de Geografía y Ciencias Sociales, XIII, 281 http://www.ub.es/geocrit/sn/sn-281.htm

Ávila, R.; Iniesta, A.; Herrero, D.; De Juan, J.; Aguirre, G.; Guereña, A.; Morera, C.; Beluche, G.; Aguilar, P.; Zambrano, D.; Ruiz, R.; Buglass, L.; Kamp, C. y Giraldo, A., 2002. Turismo sostenible. Madrid: IEPALA.

Ayuntamiento de Zaragoza, 2012. Actualización de los Indicadores de Sostenibilidad de Zaragoza 2012. Agenda 21 Zaragoza. Cuaderno no 20. Zaragoza: Ayuntamiento de Zaragoza. En línea [Acceso: 11-07-2013]: http://www.zaragoza.es/contenidos/medioambiente/indicadores2012.pdf

Ayuntamiento de Zaragoza, 2013. Portal del Observatorio Municipal de Estadística del municipio de Zaragoza. Zaragoza: Ed. Ayuntamiento de Zaragoza. En línea [Acceso: 12-07-2013]: http://demografia.zaragoza.es.

Beas Secall, L., 2012. Los planes de excelencia turística en España (1992-2006). Una apuesta por la revitalización de los destinos. Revisión de su implantación e impactos. Scripta Nova. Revista Electrónica de Geografía y Ciencias Sociales, XVI, 411 [Acceso: 22/12/2014]: http:// www.ub.es/geocrit/sn/sn-411.htm

Bermejo, R. y Nebreda, A., 1998). Conceptos e instrumentos para la sostenibilidad local. Cuadernos Bakeaz, 26, 1-18.

Blancas, F.J.; González, M.; Guerrero, F.M. y Lozano, M., 2010. Indicadores sintéticos de turismo sostenible: una aplicación para los destinos turísticos de Andalucía. Revista Electrónica de Comunicaciones y Trabajos de ASEPUMA, 11, 85-118.

Callizo, J. y Lacosta, A., 2006. Zaragoza como producto turístico urbano-cultural: arte, ferias, congresos y negocios. Edición digital de Actas: IV Coloquio de Geografía Urbana y VI Coloquio 
de Geografía del Turismo, Ocio y Recreación: Las Palmas de Gran Canaria, 22 al 24 de junio de 1998. Ayuntamiento de Las Palmas de Gran Canaria, Asociación de Geógrafos Españoles, 2000, pp. 176-187.

Canizares Ruiz, M ${ }^{a}$ C., 2013. Sostenibilidad y turismo: de la documentacion internacional a la planificacion en Espana "Horizonte 2020". Boletin de Asociación de Geógrafos Españoles, 61, 67-92.

Castro, J., 2002. Indicadores de Desarrollo Sostenible Urbano. Una aplicación para Andalucía. Málaga: Universidad de Málaga.

Choi, H. y Sirakaya, E. (2005). Sustainability indicators for managing community tourism. Tourism Management, 27 (6), 1274-1289.

De Esteban, J., 2008. Turismo cultural y medio ambiente en destinos urbanos. Madrid: Dykinson.

EBRÓPOLIS, 2008-2013. Portal de EBROPÓLIS. Cuadro de mando de la Estrategia 2020 de Zaragoza y su entorno, 2008-2013. Zaragoza: Ed. EBRÓPOLIS. En línea [Acceso: 11-07-2013]: http://cuadrodemando.ebropolis.es/bienvenida.php

FEMP, 2002. Código de Buenas Prácticas Ambientales. Madrid: Federación Española de Municipios y Provincias. En línea [Acceso: 23-10-3013]: http://www.redmur21.com/UPLOAD/DOCUMENTO/codigo_buenas_practicas_femp.pdf

García Hernández, M., 2000. Turismo y medio ambiente en ciudades históricas: la capacidad de acogida turística y la gestión de los flujos de visitantes. Anales de Geografía de la Universidad Complutense, 20, 131-148.

Garcia Hernandez, M., 2003. Turismo y conjuntos monumentales. Capacidad de acogida turistica y gestion de flujos de visitantes. Valencia: Tirant lo Blanch.

Garcia Hernandez, M., 2007. Entidades de planificacion y gestion turistica a escala local. El caso de las ciudades patrimonio de la humanidad de Espana. Cuadernos de Turismo, 20, 79-102.

García, M., y de la Calle, M., 2012. Capacidad de carga en grandes recursos turístico-culturales. Anales de Geografía, 2, 32, 253-274.

Garcia Hernandez, M.; de la Calle Vaquero, M. y Minguez Garcia, M…., 2011. Capacidad de carga turistica y espacios patrimoniales. Aproximacion a la estimacion de la capacidad de carga del conjunto arqueológico de Carmona (Sevilla, Espana). Boletín de Asociación de Geógrafos Españoles, 57, 219-241.

Gomila, M․ Fª , 2000. La Agenda 21 Local de Calvià. En Font, N. y Subirats, J. (eds) Local y sostenible. La Agenda 21 Local en España. Colecc. Ecología Humana. Barcelona: Icaria, 209-243.

Gonzalez, F.; Martin, F. y Fernandez, M., 2004. Medicion del desarrollo sostenible y analisis regional: diseno y aplicación de un indice sintético global a las comunidades autonomas espanolas. Investigaciones Regionales, 5, 91-112.

Gooroochurn, N. y Sugiyarto, G., 2005. Competitiveness indicators in the travel and tourism industry. Tourism Economics, 11 (1), 25-43.

Gutierez-Fernandez, F.; Cloquell Ballester, V.A. y Cloquell Ballester, V, 2012. Propuesta de un sistema de indicadores de sostenibilidad para áreas naturales con uso turístico, validado mediante consulta a terceros. Anuario Turismo y Sociedad, XIII, 55-83. 
Ibanez, R. y Angeles, M., 2012. Indicadores de sustentabilidad turistica en Mexico. En: Ivanova, A. e Ibanez, R. (coord) Medio ambiente y politica turistica en Mexico. Tomo I: Ecologia, biodiversidad y desarrollo turistico. México: Secretaria de Medio Ambiente y Recursos Naturales, 47-66.

INE, 2006-2012. Encuesta Ocupación Hotelera. Madrid: Instituto Nacional de Estadística.

INE, 2013. El peso de la actividad turística en 2012 alcanzó el 10,9\% del PIB y el 11,9\% del empleo. Notas de prensa. Madrid: Instituto Nacional de Estadística.

IUCN, 2001. Resource kit for sustentability assessment. International Union for Conservation of Nature and Natural Resources. Suiza: Gland.

Ivars, J.A., 2001. Planificación y gestión del desarrollo turístico sostenible: propuestas para la creación de un sistema de indicadores, $\mathrm{n}^{\mathrm{o}}$ 1, Documentos de Trabajo. Alicante: Instituto Universitario de Geografía, Universidad de Alicante.

Jimenez, A. e Hirabayashi, Y., 2003. De la teoria a la practica en la sustentabilidad y la participacion comunitaria: una propuesta metodologica. En: Cappaci, A (comp) Paisaje, ordenamiento territorial y turismo Sostenible. Génova: Universidad degli Studi di Genova, 81-97.

Lim, C. y McAleer, M., 2005. Ecologically sustainable tourism management. Environmental Modelling \& Software, 20, 1431-1438.

Mazaro, R.M. y Varzin, G., 2008. Competitiveness Models for Tourist Destinations into the Sustainability Context. RAC, Curitiba, 12 (3), 789-809.

Ministerio de Agricultura, Alimentación y Medio Ambiente, 2012. Informe del Inventario Nacional de emisiones de GEI, años 1990-2011. Madrid: Gobierno de España.

OCDE, 1997. Better Understanding our Cities. The Rule of Urban Indicators. Paris: OCDE.

OCDE, 2003. Environmental indicators, Development, Measurement and use. Francia: Organización para la Cooperación y el Desarrollo Económico. En línea [Acceso: 15-07-2013]: http:// www.oecd.org/environment/indicators-modelling-outlooks/24993546.pdf

OMT, 1978. Evaluación de los recursos turísticos. Madrid: Organización Mundial de Turismo.

OMT, 1995. Lo que todo gestor turistico debe saber. Guia practica para el desarrollo y uso de indicadores de turismo sostenible. Madrid: Organizacion Mundial del Turismo.

OMT, 2005. Indicadores de desarrollo sostenible para los destinos turisticos. Guia practica. Madrid: Organizacion Mundial del Turismo.

OMT, 2013. Panorama OMT del turismo internacional. Madrid: Organización Mundial del Turismo.

Palafox Munoz, A. y Segrado Pavon, R.G., 2008. El Observatorio del Turismo, base para el Centro de Articulacion Productiva de Turismo de Quintana Roo. Teoria y Praxis, 5, 161-170.

Pardellas de Blas, X.X., y Pandin Fadeiro, C., 2004. Una propuesta de turismo sostenible para el municipio de Caldas de Reis (Pontevedra). Cuadernos de Turismo, 13, 107-125.

Pellicer Corellano, F., 2008. Expo Zaragoza 2008: la metamorfosis de las riberas del Ebro. Economía Aragonesa, 37, 54-74.

Pérez, V.E.; Blancas, F.J.; González, M.; Guerrero, M.; Lozano, M.; Pérez, F. y Caballero, R.E., 2009. Evaluación de la sostenibilidad del turismo rural mediante indicadores sintéticos. Revista Investigación Operacional, 30, 1, 40-51. 
PNUMA-OMT, 2006. Por un turismo más sostenible. Guía para responsables políticos. París-Madrid: Programa de las Naciones Unidas para el Medio Ambiente (PNUMA) y la Organización Mundial del Turismo (OMT).

Prados Pérez, E., 2002. Medio ambiente y turismo, dos realidades sinérgicas en el nuevo milenio. Derecho y Medio Ambiente, III, 9, 53-95.

Pueyo, A., 2007. Zaragoza y la EXPO 2008. Estudios Geográficos, LXVIII, 262, 359-362.

Pulido, J.I. y Sánchez, M., 2007. Propuesta metodologica para el diseno de un indice sintetico de turismo sostenible. Papers de Turisme, 2, 27-41.

Quiroga Martínez, R., 2007. Indicadores ambientales y de desarrollo sostenible: avances y perspectivas para América Latina y el Caribe. Serie Manuales, 55. Santiago de Chile: CEPAL-ONU, División de Estadística y Proyecciones Económicas.

Ritchie, J.R.B. y Crouch, G.I., 2003. The Competitive Destination. A Sustainable tourism perspective. UK: CABI Publishing.

Rivas, J. y Magadán, M., 2007. Los indicadores de sostenibilidad en el turismo. Revista de Economia, Sociedad, Turismo y Medio Ambiente- RESTMA, 6, 26-61.

Ruiz, E. y De la Cal, P., 2008. EXPOZARAGOZA 2008, ríos y puentes como eje de transformación urbanística. Revista de Obras Públicas, 3.490, 15-22.

Salinas Chavez, E. y La O Osorio, J.A., 2006. Turismo y sustentabilidad: de la teoría a la práctica en Cuba. Cuadernos de Turismo, 17, 201-221.

Sancho, A. y García, G., 2006. ¿Qué indica un indicador?. Análisis comparativo en los destinos turísticos. Revista de Análisis Turístico, 2, 69-85.

Troitiño, M.A., 1998. Turismo y desarrollo sostenible en ciudades históricas. Ería: Revista Cuatrimestral de Geografía, 47, 211-228.

Troitiño, M.A., 2000. Ciudades históricas y turismo: los desafíos de la sostenibilidad. Mérida, Ciudad y Patrimonio. Revista de Arqueología, Arte y Urbanismo, 4, 93-108.

Troitiño, M.A., 2008. Ciudades Patrimonio de la Humanidad: Patrimonio, Turismo y Recuperación Urbana. Sevilla: Universidad Internacional de Andalucía.

Troitino, M.A. et al., 1999. Estudio previo para la revision del Plan Especial de la Alhambra y Alijares. Granada: Patronato de la Alhambra y el Generalife.

Troitiño, M.A.; De la Calle, M. y García, M., 2008. Observatorio Turístico del Grupo de Ciudades Patrimonio de la Humanidad de España. Ávila: Grupo de Ciudades de Patrimonio de la Humanidad de España. En línea [Acceso: 11-09-2013]: http://www.ciudadespatrimonio.org/publicaciones/1293707576_Informe2008.pdf

UrbanTur, 2013. Monitor de competitividad turística de los destinos urbanos españoles. Madrid: Exceltur.

Vera Rebollo, J.F., 1992. La dimensión ambiental de la planificación turística: una nueva cultura para el consumo turístico. Papers de Turisme, 10, 25-40.

Villa, G., 2000. Taller de indicadores de sostenibilidad en turismo para los países de Sudamérica. Madrid: Organización Mundial de Turismo. 
Yunis, E. 2003. El marco internacional de la gestion sostenible del turismo: la vision de la Organizacion Mundial del Turismo. A DISTANCIA. Monografico "Turismo y sostenibilidad", 21.

Zaragoza Turismo, 2011. Plan Estratégico Zaragoza Turismo 2011-2016. Zaragoza: Ayuntamiento de Zaragoza.

Zaragoza Turismo, 2012. Informe anual de Turismo Zaragoza 2012. Zaragoza: Ayuntamiento de Zaragoza.

Zaragoza Turismo, 2013a. Informe anual de Turismo Zaragoza 2013. Zaragoza: Ayuntamiento de Zaragoza.

Zaragoza Turismo, 2013b. Portal de Zaragoza Turismo. Información sobre servicios, gastronomia, compras, rutas en la ciudad y guía práctica para viajar a Zaragoza. Zaragoza: Ayuntamiento de Zaragoza. En línea [Acceso: 12-03-2013]: http://www.zaragoza.es/turismo/ 